\title{
Effect of Distribution Generators on Stability in a Limited Bus Power Grid System
}

\author{
Nader Barsoum, Christoper Bin Asok, David Ting Szu Kwong, Clifford Gan Thien Kit \\ Department of Electrical and Electronic Engineering, University Malaysia Sabah, Kota Kinabalu, Malaysia \\ Email:nnb3@hotmail.com
}

How to cite this paper: Barsoum, N., Asok, C.B., Kwong, D.T.S. and Kit, C.G.T. (2017) Effect of Distribution Generators on Stability in a Limited Bus Power Grid System. Journal of Power and Energy Engineering, 5, 74-91.

https://doi.org/10.4236/jpee.2017.59007

Received: June 28, 2017

Accepted: September 12, 2017

Published: September 15, 2017

Copyright () 2017 by authors and Scientific Research Publishing Inc. This work is licensed under the Creative Commons Attribution International License (CC BY 4.0).

http://creativecommons.org/licenses/by/4.0/

\begin{abstract}
It has been recognized recently that when injecting renewable energy source power to a load bus which connected to a distributed feeder in a power grid system, a stability problem occurs particularly when having high fault duties that exceeding the circuit breaker ratings at some substations. In this paper an analysis of power flow, short circuit, stability and protection is given in detail to an example of limited 7-bus power grid system. Comparison is illustrated between power grid with and without distributed generators regarding bus voltages, fault currents, critical power angles, selected current transformers and over current relay settings in each bus.
\end{abstract}

\section{Keywords}

Power Grid, Bus Voltages, Fault Currents, Critical Angle, Critical Clearing Time, Over Current Relay Setting

\section{Introduction}

Recently, it is noticed that stability problem in power generation and relay setting problem occur due to high fault in distribution feeders which may be probably caused by injecting a distribution generator in the load buses. Consumers like to use renewable energy sources installed in their home, factories, hospitals or moles and get a license to connect them to the power grid. The connection is found to be at distribution feeders which connected to the substation buses. This causes sometimes high fault duty and instability in the grid as well as exceeding the values of relay rate in some substations.

Normally the power system stability is analyzed in terms of bus voltages at steady-state and during fault and determined by critical clearing angle [1]. The phenomenon of bus voltage collapse due to a dynamic load in the power network is analyzed by simple power system model [2]. This voltage instability can 
also be analyzed by transferring the system model into a singular perturbation theory and solved by numerical investigation [3]. This voltage dropping at transient during fault leads to system disruption, which may be due to the maximum load power transfer from generation stations to load buses. Contingency analysis was presented in [4] and shows the post-contingency load flow and modified load flows in time domain. The contingency analysis and post-contingency analysis were used for long-term voltage stability; the credible contingencies are outages of transmission and generation facilities, in which a system must be able to withstand any single transmission or generation outage.

In this paper stability analysis is given for a simple limited 7-bus grid when a symmetrical 3-phase fault occurs at each bus. Comparisons between network with and without distribution generators are illustrated. This investigates the stability problem and avoided by calculating the critical angle and the corresponding critical clearing time to set up the over current relay at each bus.

The analysis started by load flow [5] using Gauss-Seidel method to calculate the optimum bus voltages by selecting suitable slack bus in the system. This is followed by calculating the fault current and the corresponding bus voltages at transient [6] considering the bus impedance matrix which is the inverse of the bus admittance matrix. Stability analysis is represented by calculating the critical angle in each bus based on the reactance values of the diagonal in the bus impedance matrix and the pre-fault bus voltages from load flow results with the transient voltages during fault from the short circuit results [7]. This is followed by the calculation of the critical clearing time assuming a constant moment of inertia in all turbine-generator system. This time is used for setting the relay and circuit breaker at each bus [8].

\section{Power Grid Model}

An example is taken for this analysis represented by a simple power network [8]. It consists of 7 buses; the first 2 are considered fusel fuel power stations referred to generating bus which generates $22 \mathrm{kV}$ each. The next 3 buses are transmission busses include 5 transformers and 4 transmission lines ( 3 medium with $275 \mathrm{kV}$ and one short with $132 \mathrm{kV}$ ). The last 2 are the distribution buses, one for heavy industrial area and one for residential area. Bus 6 step down from $33 \mathrm{kV}$ to 11 $\mathrm{kV}$ in 3 distributed feeders and then to $400 \mathrm{~V}$ to the shop moles, hospitals and schools. Bus 7 is connected to 20 distributed feeders with $6.6 \mathrm{kV}$ each then step down to $400 \mathrm{~V}$ to about 85 houses or flat units or shops in each feeder. These 2 bus loads are combined in one total load in each bus as shown in Figure 1. The consumers in these 2 areas like to install a renewable energy sources in each feeder connected to the grid. These are represented by distributed generators connected to the bus 6 and 7 giving the total power generation values as shown in Figure 2. In order to investigate the process of calculation of power and line flow, the powers of the distributed generators (DG) are considered to be less than the power of loads in bus 6 and 7 . 


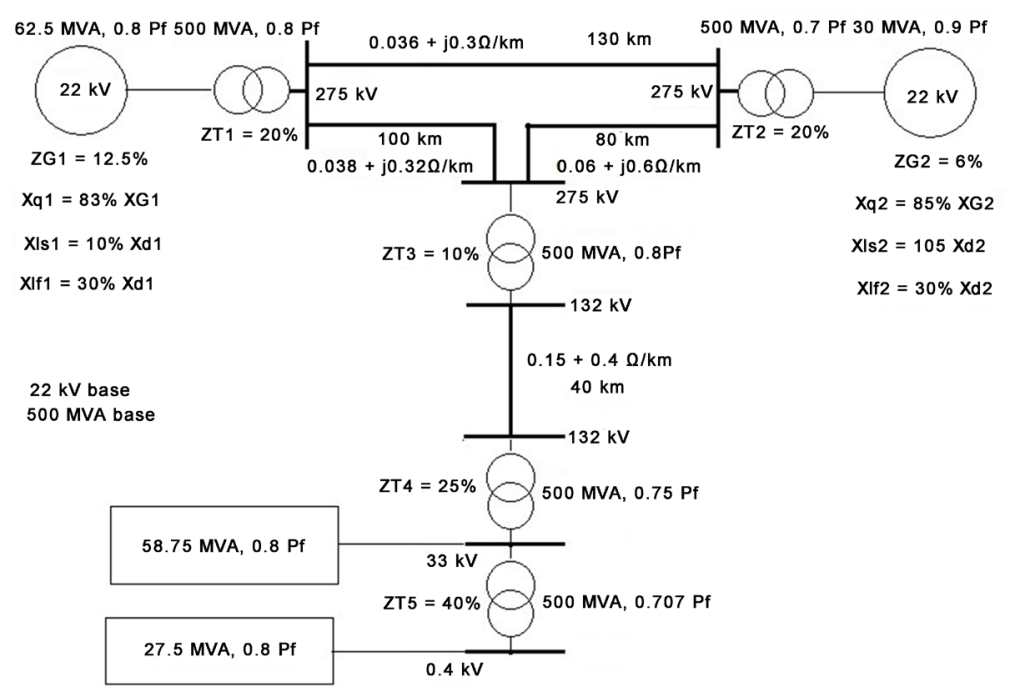

Figure 1. 7-bus power grid system without distributed generators.

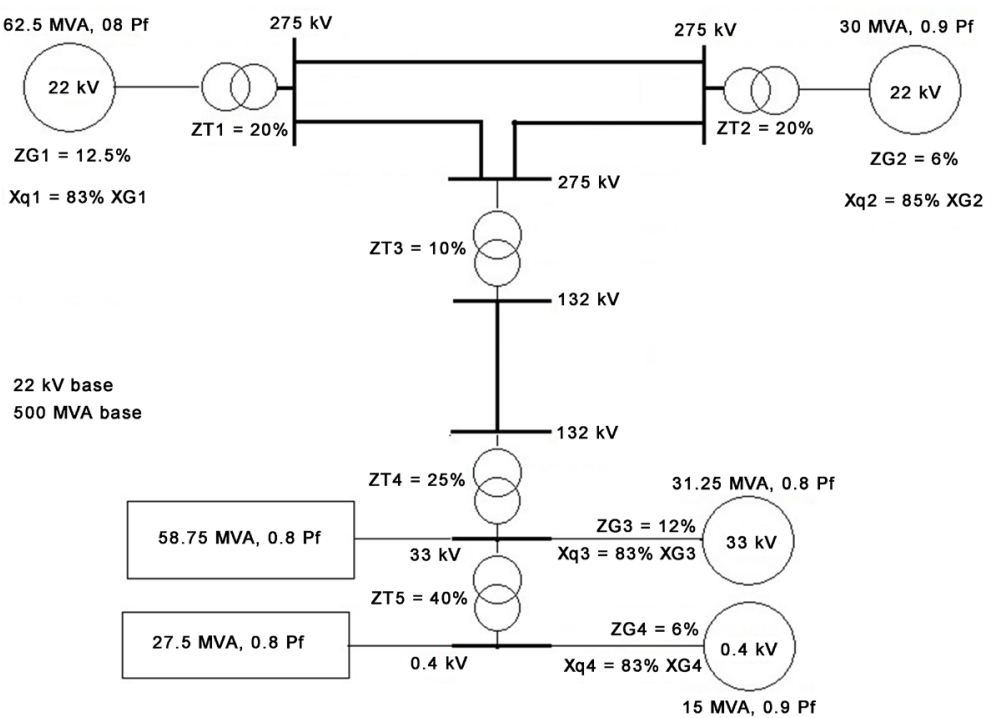

Figure 2. 7-bus power grid system with distributed generators.

The per unit values of power, admittance and impedance of all components in the grid can be calculated from its concept. These values are given in the network of Figure 3. Admittance and impedance matrices can be easily obtained, as in (1), (2), (3), (4).

$\left[\begin{array}{ccccccc}1.68-j 8.99 & 0.45-j 3.79 & 0.56-j 4.7 & 0 & 0 & 0 & 0 \\ 0.45-j 3.79 & 2.04-j 9.32 & 0.86-j 5.12 & 0 & 0 & 0 & 0 \\ 0.56-j 4.7 & 0.86-j 5.12 & 9.42-j 15.82 & 8-j 6 & 0 & 0 & 0 \\ 0 & 0 & 8-j 6 & 8.71-j 7.91 & 0.71-j 1.91 & 0 & 0 \\ 0 & 0 & 0 & 0.71-j 1.91 & 3.63-j 4.53 & 2.92-j 2.62 & 0 \\ 0 & 0 & 0 & 0 & 2.92-j 2.62 & 4.8-j 4.48 & 1.79-j 1.79 \\ 0 & 0 & 0 & 0 & 0 & 1.79-j 1.79 & 1.83-j 1.82\end{array}\right]$

Bus admittance matrix without distributed generator (1) 


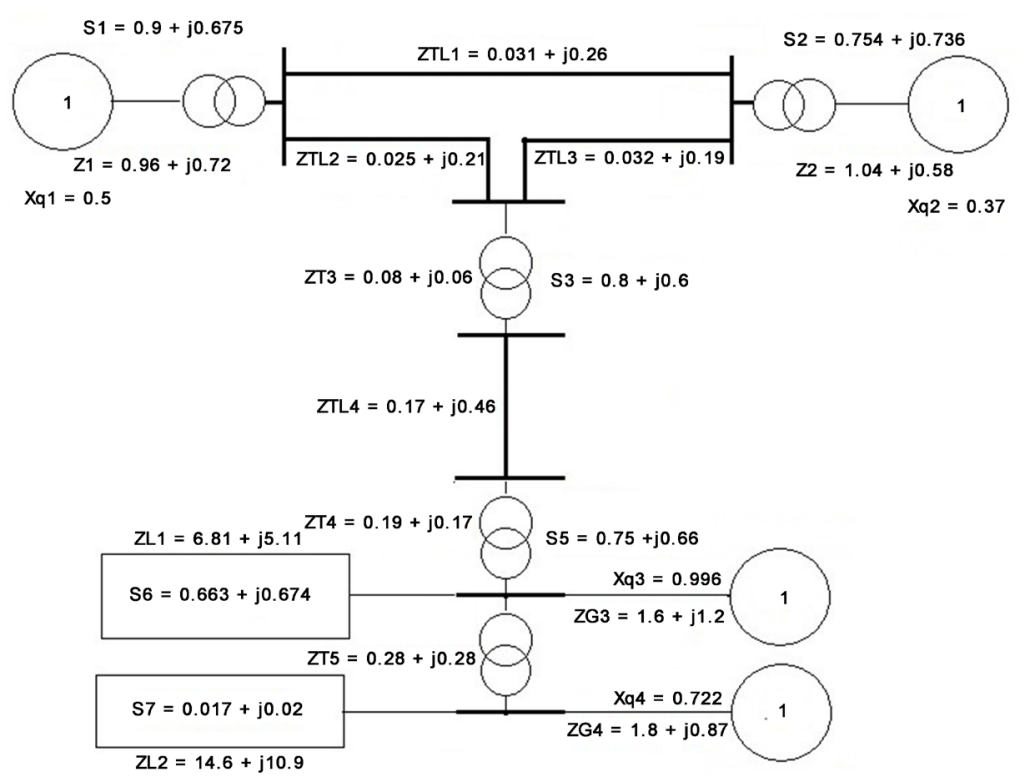

Figure 3. Per unit powers, voltages and impedances.

\begin{tabular}{lllllll}
\hline $0.4602+\mathrm{j} 0.3429$ & $0.4515+\mathrm{j} 0.2667$ & $0.4544+\mathrm{j} 0.29$ & $0.4474+\mathrm{j} 0.2908$ & $0.4293+\mathrm{j} 0.2549$ & $0.4125+\mathrm{j} 0.2428$ & $0.4045+\mathrm{j} 0.236$ \\
$0.4515+\mathrm{j} 0.2667$ & $0.4694+\mathrm{j} 0.3402$ & $0.4579+\mathrm{j} 0.29$ & $0.4508+\mathrm{j} 0.293$ & $0.4326+\mathrm{j} 0.2569$ & $0.4157+\mathrm{j} 0.2447$ & $0.4075+\mathrm{j} 0.238$ \\
$0.4544+\mathrm{j} 0.2949$ & $0.4579+\mathrm{j} 0.2973$ & $0.4693+\mathrm{j} 0.38$ & $0.4620+\mathrm{j} 0.381$ & $0.4464+\mathrm{j} 0.3389$ & $0.4292+\mathrm{j} 0.3233$ & $0.4211+\mathrm{j} 0.315$ \\
$0.4474+\mathrm{j} 0.2908$ & $0.4508+\mathrm{j} 0.2931$ & $0.4620+\mathrm{j} 0.38$ & $0.5335+\mathrm{j} 0.434$ & $0.5154+\mathrm{j} 0.3864$ & $0.4955+\mathrm{j} 0.3685$ & $0.4860+\mathrm{j} 0.359$ \\
$0.4293+\mathrm{j} 0.2549$ & $0.4326+\mathrm{j} 0.2569$ & $0.4464+\mathrm{j} 0.33$ & $0.5154+\mathrm{j} 0.386$ & $0.6738+\mathrm{j} 0.7653$ & $0.6488+\mathrm{j} 0.7312$ & $0.6372+\mathrm{j} 0.713$ \\
$0.4125+\mathrm{j} 0.2428$ & $0.4157+\mathrm{j} 0.2447$ & $0.4292+\mathrm{j} 0.32$ & $0.4955+\mathrm{j} 0.368$ & $0.6488+\mathrm{j} 0.7312$ & $0.8053+\mathrm{j} 0.8606$ & $0.7907+\mathrm{j} 0.840$ \\
$0.4045+\mathrm{j} 0.2364$ & $0.4075+\mathrm{j} 0.2383$ & $0.4211+\mathrm{j} 0.31$ & $0.4860+\mathrm{j} 0.359$ & $0.6372+\mathrm{j} 0.7138$ & $0.7907+\mathrm{j} 0.8401$ & $1.0536+\mathrm{j} 1.092$ \\
\hline
\end{tabular}

Bus impedance matrix without distributed generator (2)

$\left[\begin{array}{ccccccc}1.68-j 8.99 & 0.45-j 3.79 & 0.56-j 4.7 & 0 & 0 & 0 & 0 \\ 0.45-j 3.79 & 2.04-j 9.32 & 0.86-j 5.12 & 0 & 0 & 0 & 0 \\ 0.56-j 4.7 & 0.86-j 5.12 & 9.42-j 15.82 & 8-j 6 & 0 & 0 & 0 \\ 0 & 0 & 8-j 6 & 8.71-j 7.91 & 0.71-j 1.91 & 0 & 0 \\ 0 & 0 & 0 & 0.71-j 1.91 & 3.63-j 4.53 & 2.92-j 2.62 & 0 \\ 0 & 0 & 0 & 0 & 2.92-j 2.62 & 5.2-j 4.78 & 1.79-j 1.79 \\ 0 & 0 & 0 & 0 & 0 & 1.79-j 1.79 & 2.28-j 2.04\end{array}\right]$

Bus admittance matrix with distributed generator (3)

\begin{tabular}{lllllll}
\hline $0.3657+\mathrm{j} 0.3075$ & $0.3563+\mathrm{j} 0.231$ & $0.3536+\mathrm{j} 0.243$ & $0.3311+\mathrm{j} 0.232$ & $0.2680+\mathrm{j} 0.126$ & $0.2140+\mathrm{j} 0.093$ & $0.1806+\mathrm{j} 0.0672$ \\
$0.3563+\mathrm{j} 0.2310$ & $0.3735+\mathrm{j} 0.304$ & $0.3562+\mathrm{j} 0.245$ & $0.3336+\mathrm{j} 0.234$ & $0.2701+\mathrm{j} 0.127$ & $0.2157+\mathrm{j} 0.094$ & $0.1819+\mathrm{j} 0.0678$ \\
$0.3536+\mathrm{j} 0.2434$ & $0.3562+\mathrm{j} 0.245$ & $0.3634+\mathrm{j} 0.316$ & $0.3398+\mathrm{j} 0.301$ & $0.2828+\mathrm{j} 0.175$ & $0.2268+\mathrm{j} 0.131$ & $0.1928+\mathrm{j} 0.0980$ \\
$0.3311+\mathrm{j} 0.2323$ & $0.3336+\mathrm{j} 0.234$ & $0.3398+\mathrm{j} 0.301$ & $0.3925+\mathrm{j} 0.343$ & $0.3262+\mathrm{j} 0.199$ & $0.2616+\mathrm{j} 0.149$ & $0.2223+\mathrm{j} 0.1113$ \\
$0.2680+\mathrm{j} 0.1267$ & $0.2701+\mathrm{j} 0.127$ & $0.2828+\mathrm{j} 0.175$ & $0.3262+\mathrm{j} 0.199$ & $0.4411+\mathrm{j} 0.414$ & $0.3571+\mathrm{j} 0.316$ & $0.3085+\mathrm{j} 0.2442$ \\
$0.2140+\mathrm{j} 0.0934$ & $0.2157+\mathrm{j} 0.094$ & $0.2268+\mathrm{j} 0.131$ & $0.2616+\mathrm{j} 0.149$ & $0.3571+\mathrm{j} 0.316$ & $0.4405+\mathrm{j} 0.369$ & $0.3796+\mathrm{j} 0.2845$ \\
$0.1806+\mathrm{j} 0.0672$ & $0.1819+\mathrm{j} 0.067$ & $0.1928+\mathrm{j} 0.098$ & $0.2223+\mathrm{j} 0.111$ & $0.3085+\mathrm{j} 0.244$ & $0.3796+\mathrm{j} 0.284$ & $0.5710+\mathrm{j} 0.4345$ \\
\hline
\end{tabular}

Bus impedance matrix with distributed generator (4) 
Admittance matrix is determined from (A1), where the different in values between (1) and (3) is found in the last 2 columns and rows, which are related to the distribution busses. While the impedance matrix (A2) which is the inverse of the admittance matrix shows quite different in element values between (2) and (4).

\section{Load Flow Investigation}

Gauss-Seidel method is applied to this power network in both cases, with and without distributed generators. A numerical solution for the per unit bus voltages at steady-state is performed from (A3) using MATLAB program for this particular system. The solution of voltage values in each bus is repeated 7 times for a selected slack bus with 1 per unit voltage. Table 1 shows the bus voltage values when selecting each bus as slack.

It can be seen from Table 1 that the realistic values of voltages at load buses 6 and 7 are smaller than the values of generating bus 1 and 2. Slack bus 5, 6 and 7 satisfy this property. However, the optimum values of bus voltages are the values that are very close to 1 per unit in order to have minimum line losses. Hence bus 5 is the suitable bus to be selected as slack. Similar result is obtained for grid with distributed generators connected to bus 6 and 7. Figure 4 shows the comparison of the magnitude of bus voltages when bus 5 is slack. It shows that voltage value of bus 6, 7 in case of distributed generators have less value of the case without DG.

The number of iterations to reach the accuracy of Gauss method is compared between the 2 cases in Figure 5.

The analysis is processed to evaluate the bus current from (A4) and the generator voltages $\mathrm{E}=$ bus voltage $\mathrm{V}+$ the voltage drop in the transformer and generator impedance. It is illustrated in Figure 6. Current flows in the 4 lines are obtained and the magnitudes of line flow and line loss are calculated from (A5), (A6) and shown in Figure 7, Figure 8. It is noted from Figure 8 that the line loss is smaller when selecting bus 5 as slack than any other slack bus.

Table 1. Bus voltages magnitude with different slack bus for the grid without distributed generators.

\begin{tabular}{cccccccc}
\hline Bus & V. 1 & V. 2 & V. 3 & V. 4 & V. 5 & V. 6 & V. 7 \\
\hline Generator 1 & 1 & 1.106 & 1.037 & 1.115 & 1.254 & 1.329 & 1.415 \\
Generator 2 & 1.127 & 1 & 1.045 & 1.123 & 1.263 & 1.338 & 1.426 \\
Transmis. 3 & 1.195 & 1.182 & 1 & 1.097 & 1.269 & 1.360 & 1.465 \\
Transmis. 4 & 1.272 & 1.259 & 1.091 & 1 & 1.229 & 1.347 & 1.482 \\
Transmis. 5 & 1.662 & 1.653 & 1.520 & 1.458 & 1 & 1.238 & 1.504 \\
Distribute 6 & 1.714 & 1.706 & 1.587 & 1.53 & 1.137 & 1 & 1.381 \\
Distribute 7 & 1.668 & 1.660 & 1.543 & 1.48 & 1.096 & 0.958 & 1 \\
\hline
\end{tabular}




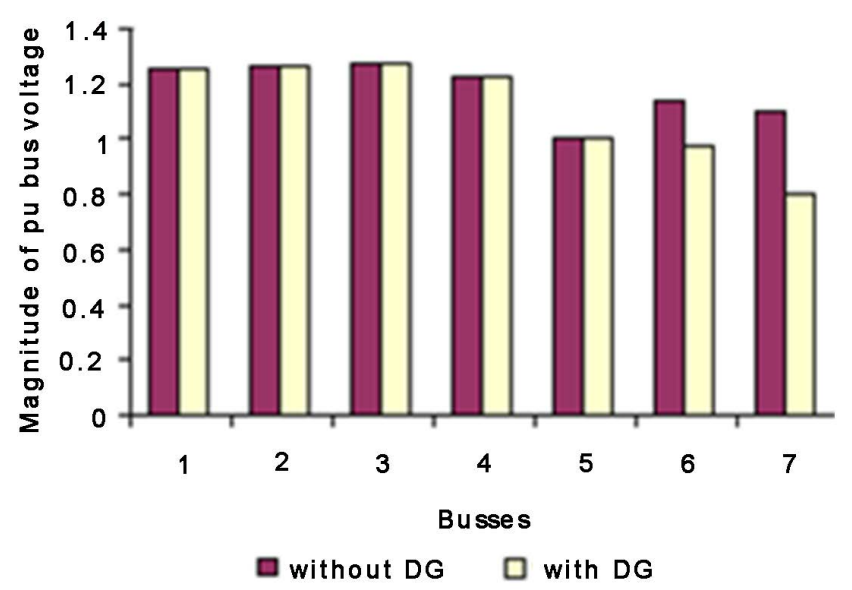

Figure 4. Magnitude of bus voltages at each bus for slack bus 5.

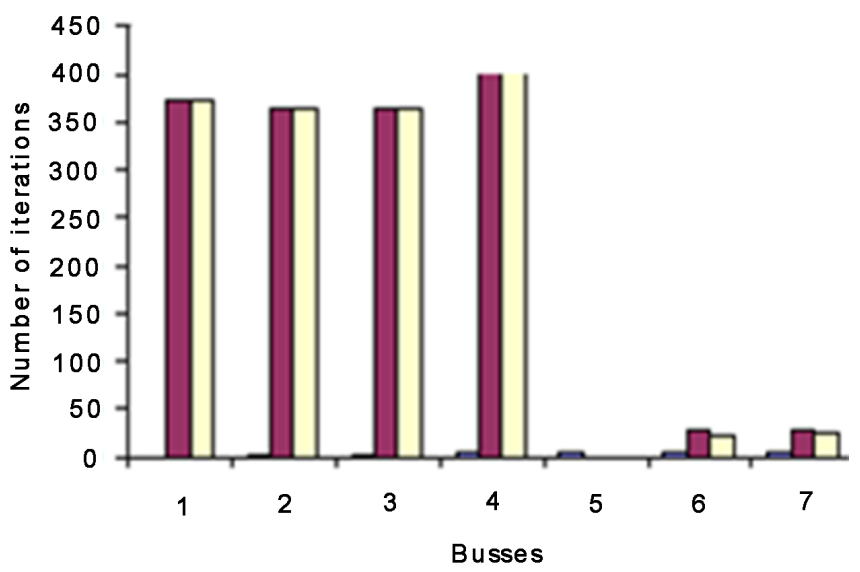

$\square$ without DG $\square$ with DG

Figure 5. Number of iterations at each bus.

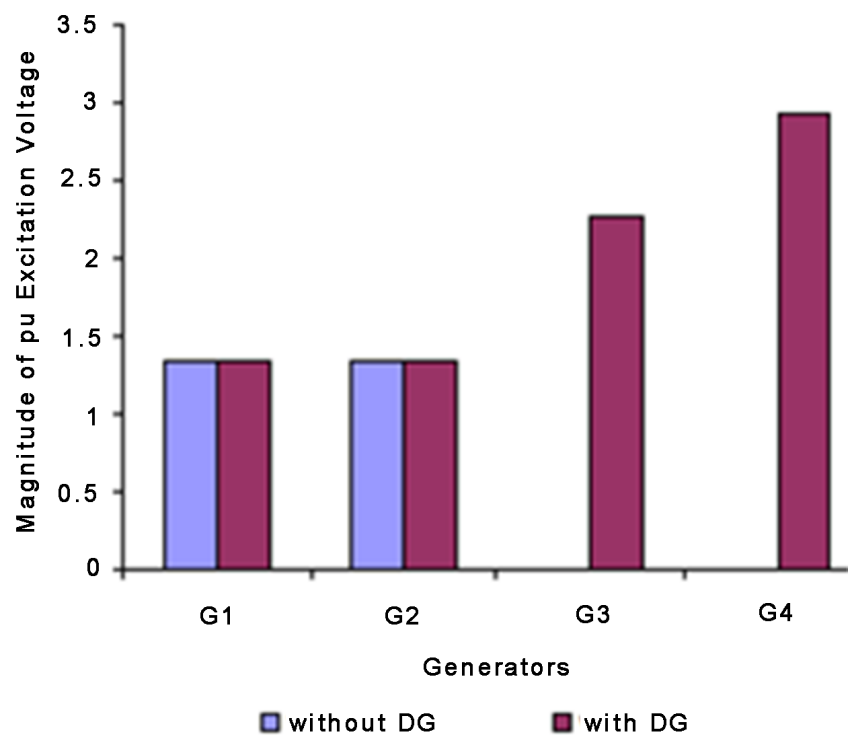

Figure 6. Magnitude of generator voltages at steady-state. 


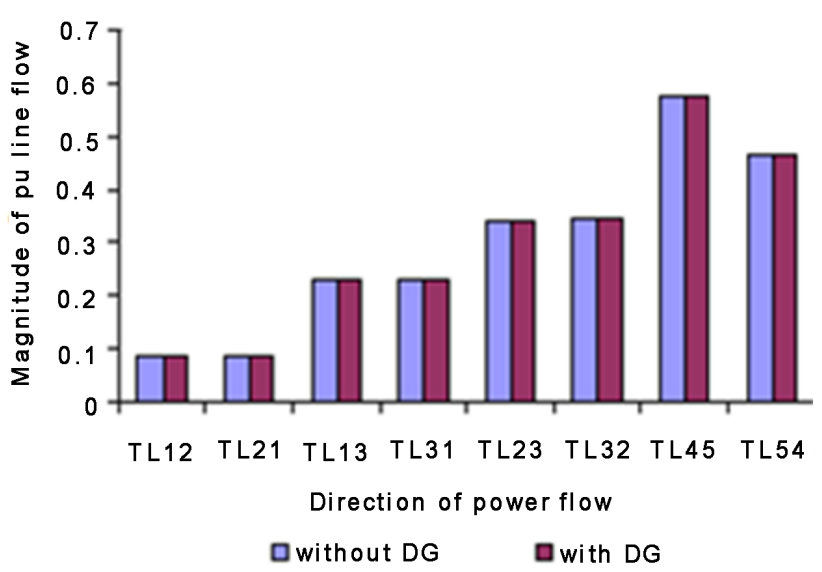

Figure 7. Magnitude of line flow power in per unit.

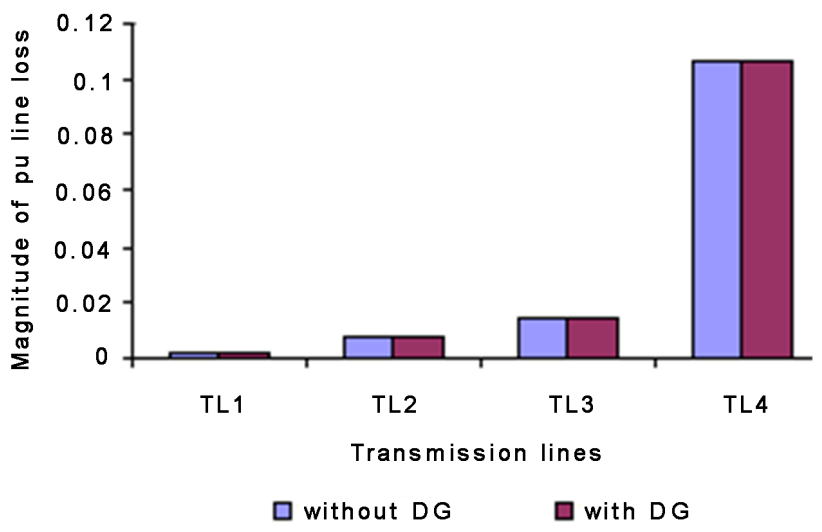

Figure 8. Magnitude of line losses at normal operation.

\section{Short Circuit Investigation}

A symmetrical 3-phase fault is used, and the calculation of fault current in each bus is obtained from (A7). Figure 9 shows the magnitude of fault currents in both cases using the diagonal of the impedance matrix (2) and (4) with the bus voltages of Figure 4. The calculation of the transient bus voltages during fault are determined from (A8) and given in Table 2 and Table 3.

In Figure 9, fault current without distributed generators in power grid network is lower than the fault current with distributed generators. It is clearly indicate that placing distributed generators at bus 6 and 7 causes an increase of the fault current at all buses.

This shows that the presence of distribution generators in a network affects the short circuit level of the network. It creates an increase in the fault currents when compared to normal conditions at which no distributed generators is installed in the network. The maximum increase is at bus bar 6 which contributed $75.25 \%$ and this seems to be quite reasonable as the distributed generators is located at this bus. The distance between the distributed generators and the fault is too small and the current is not damped at all. This close distance leads to an increase in the percentage of distributed generators contribution to the fault, 


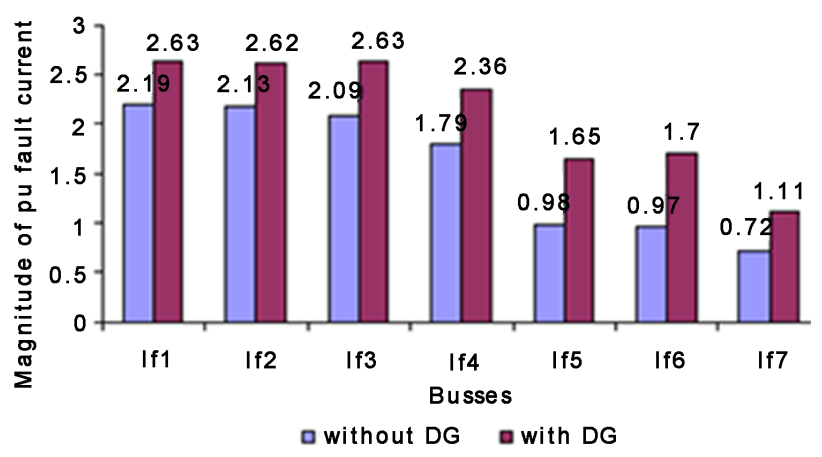

Figure 9. Magnitude of symmetric fault current at each bus.

Table 2. Fault current and transient bus voltage at each bus for the case of grid without distributed generators.

\begin{tabular}{|c|c|c|c|c|c|c|c|}
\hline Bus & 1 & 2 & 3 & 4 & 5 & 6 & 7 \\
\hline Fault & 2.19 & 2.18 & 2.09 & 1.79 & 0.98 & 0.97 & 0.72 \\
\hline Current $I_{f}$ & $\angle-39.12$ & $\angle-39.0$ & $\angle-40.28$ & $\angle-38.88$ & $\angle-48.6$ & $\angle-47.9$ & $\angle-47.4$ \\
\hline \multirow{2}{*}{ V1 } & 0 & 0.17 & 0.16 & 0.31 & 0.79 & 0.82 & 0.93 \\
\hline & $\angle 0$ & $\angle 43.32$ & $\angle 34.47$ & $\angle 8.21$ & $\angle 7.07$ & $\angle 6.03$ & $\angle 2.85$ \\
\hline \multirow{2}{*}{ V2 } & 0.16 & 0 & 0.15 & 0.31 & 0.80 & 0.82 & 0.94 \\
\hline & $\angle 38.24$ & $\angle 0$ & $\angle 29.75$ & $\angle 5.31$ & $\angle 5.95$ & $\angle 4.94$ & $\angle 1.89$ \\
\hline \multirow{2}{*}{ V3 } & 0.14 & 0.14 & 0 & 0.20 & 0.74 & 0.77 & 0.90 \\
\hline & $\angle 49.95$ & $\angle 51.67$ & $\angle 0$ & $\angle-8.45$ & $\angle 7.14$ & $\angle 7.14$ & $\angle 6.12$ \\
\hline \multirow{2}{*}{ V4 } & 0.15 & 0.15 & 0.03 & 0 & 0.63 & 0.66 & 0.81 \\
\hline & $\angle 61.99$ & $\angle 63.92$ & $\angle 132.1$ & $\angle 0$ & $\angle 12.5$ & $\angle 12.51$ & $\angle 10.87$ \\
\hline \multirow{2}{*}{ V5 } & 0.18 & 0.18 & 0.18 & 0.16 & 0 & 0.06 & 0.31 \\
\hline & $\angle 116.4$ & $\angle 118.0$ & $\angle 159.5$ & $\angle 164.8$ & $\angle 0$ & $\angle-7.15$ & $\angle-1.86$ \\
\hline \multirow{2}{*}{ V6 } & 0.17 & 0.17 & 0.05 & 0.04 & 0.18 & 0 & 0.30 \\
\hline & $\angle 52.86$ & $\angle 54.23$ & $\angle 67.65$ & $\angle 31.32$ & $\angle-5.69$ & $\angle 0$ & $\angle-2.18$ \\
\hline \multirow{2}{*}{ V7 } & 0.16 & 0.15 & 0.04 & 0.03 & 0.16 & 0.02 & 0 \\
\hline & $\angle 57.2$ & $\angle 58.84$ & $\angle 89.56$ & $\angle 47.12$ & $\angle-7.21$ & $\angle-173$ & $\angle 0$ \\
\hline
\end{tabular}

Table 3. Fault current and transient bus voltage at each bus for the case of grid with distributed generators.

\begin{tabular}{|c|c|c|c|c|c|c|c|}
\hline Bus & 1 & 2 & 3 & 4 & 5 & 6 & 7 \\
\hline Fault & 2.63 & 2.62 & 2.63 & 2.36 & 1.65 & 1.70 & 1.11 \\
\hline Current $\mathrm{I}_{\mathrm{f}}$ & $\angle-42.5$ & $\angle-42.3$ & $\angle-41.8$ & $\angle-40.9$ & $\angle-43.2$ & $\angle-42.8$ & $\angle-43.19$ \\
\hline \multirow{2}{*}{ V1 } & 0 & 0.20 & 0.16 & 0.31 & 0.79 & 0.88 & 1.06 \\
\hline & $\angle 0$ & $\angle 39.6$ & $\angle 34.47$ & $\angle 8.21$ & $\angle 7.07$ & $\angle 5.04$ & $\angle 1.60$ \\
\hline \multirow{2}{*}{$\mathrm{V} 2$} & 0.20 & 0 & 0.15 & 0.31 & 0.80 & 0.89 & 1.06 \\
\hline & $\angle 35.38$ & $\angle 0$ & $\angle 29.75$ & $\angle 5.31$ & $\angle 5.95$ & $\angle 4.03$ & $\angle 0.76$ \\
\hline \multirow{2}{*}{ V3 } & 0.21 & 0.20 & 0 & 0.20 & 0.74 & 0.84 & 1.04 \\
\hline & $\angle 42.11$ & $\angle 43.1$ & $\angle 0$ & $\angle-8.45$ & $\angle 7.14$ & $\angle 7.14$ & $\angle 5.52$ \\
\hline \multirow{2}{*}{ V4 } & 0.23 & 0.22 & 0.04 & 0 & 0.63 & 0.74 & 0.97 \\
\hline & $\angle 39.28$ & $\angle 40.0$ & $\angle 20.76$ & $\angle 0$ & $\angle 12.51$ & $\angle 12.51$ & $\angle 9.50$ \\
\hline \multirow{2}{*}{ V5 } & 0.35 & 0.34 & 0.21 & 0.19 & 0 & 0.19 & 0.57 \\
\hline & $\angle 41.91$ & $\angle 42.4$ & $\angle 48.18$ & $\angle 53.06$ & $\angle 0$ & $\angle 5.59$ & $\angle 3.72$ \\
\hline \multirow{2}{*}{ V6 } & 0.42 & 0.42 & 0.31 & 0.29 & 0.19 & 0 & 0.45 \\
\hline & $\angle 20.89$ & $\angle 21.0$ & $\angle 17.23$ & $\angle 17.78$ & $\angle-7.48$ & $\angle 0$ & $\angle 1.25$ \\
\hline \multirow{2}{*}{ V7 } & 0.34 & 0.34 & 0.25 & 0.23 & 0.15 & 0.008 & 0 \\
\hline & $\angle 18.4$ & $\angle 18.6$ & $\angle 14.94$ & $\angle 15.57$ & $\angle-10.5$ & $\angle 167.4$ & $\angle 0$ \\
\hline
\end{tabular}


consequently increasing the value of fault current. Increase in fault current at other buses is less than that at bus 6 due to the far distance of the fault location from both utility and distributed generators. The second highest fault current reported is with the fault location at bus 5 which has a fault percentage of $68.37 \%$.

Table 2, Table 3 show the magnitude of bus voltages during fault at each bus for the case of grid with and without solar power injection by using bus 5 as slack. By comparing the magnitude of bus voltage among all the buses, bus voltages nearby the bus bar which fault occurs will be increased whereas bus bar which is far apart to the fault location also increases when injecting the distributed generators. As the distance between the bus bar and the fault location increases the value of the bus voltage increases.

The generator excitation voltage values during transient state are changed according to the location of the fault. Thus, for a fault at each bus, excitation voltages of the 4 generators have different values. Figure 10 shows the generator voltage values in per unit when the fault occurs at bus 1 in the 2 cases.

Current flow, line flow and line losses are also calculated in each transmission line when the fault occurs at each bus. Figure 11, Figure 12 illustrate the line loss in the 4 lines at each bus fault occurrence.

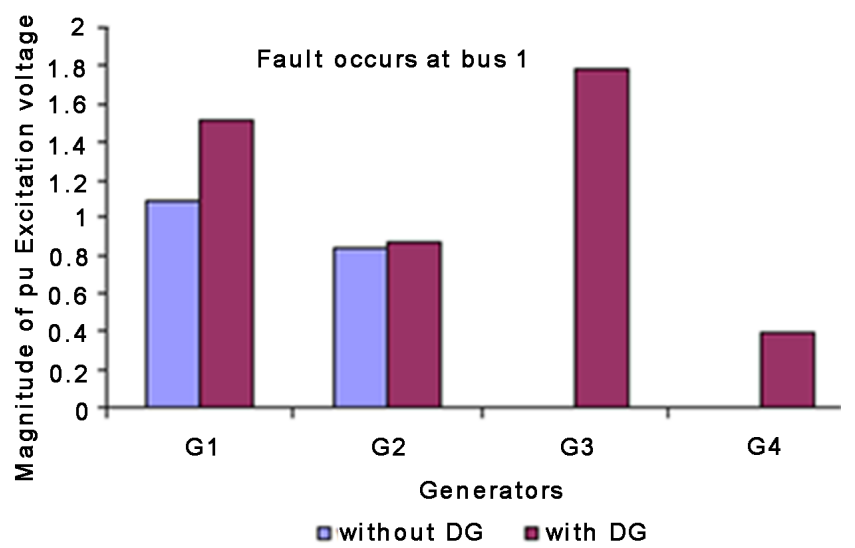

Figure 10. Magnitude of generator voltages at transient.

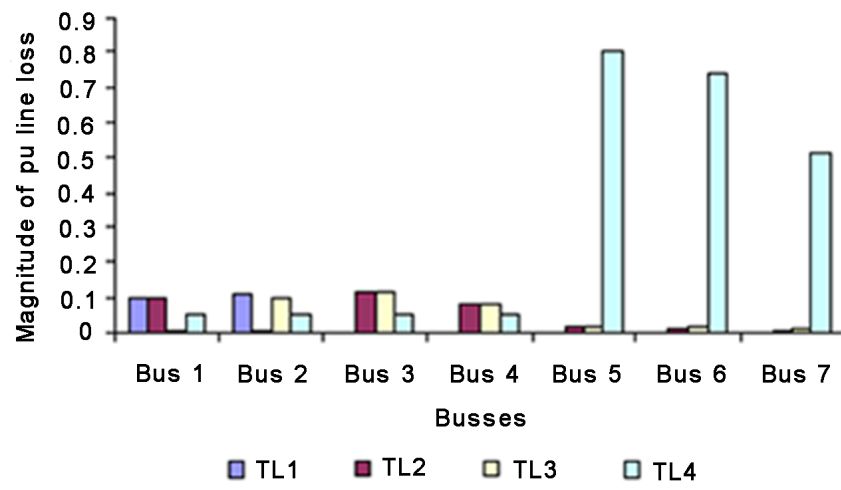

Figure 11. Line loss for a grid without DG using bus 5 as slack. 


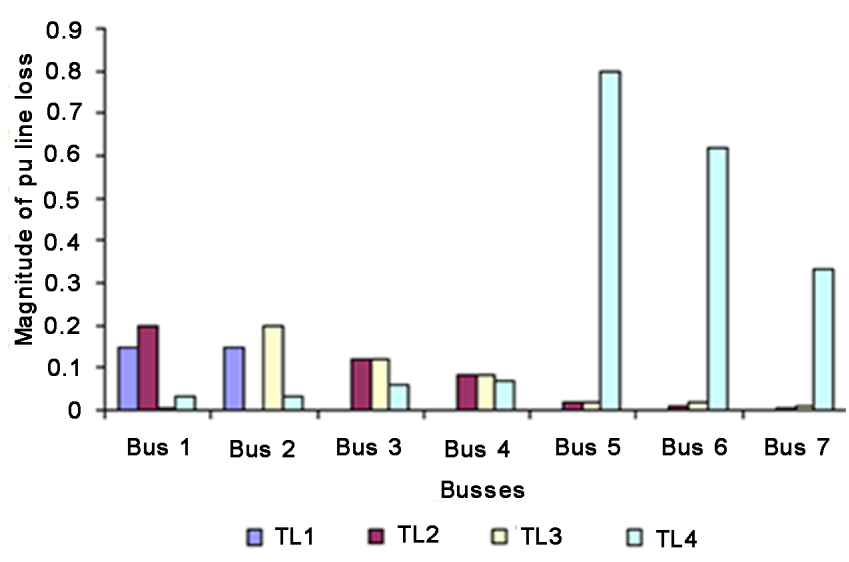

Figure 12. Line loss for a grid with DG using bus 5 as slack.

The figures show the magnitude of line loss in each transmission lines during fault at each bus for the case of grid with and without distributed generators by using bus 5 as slack. By comparing the power loss at bus 5, 6 and 7, the magnitude of power loss is observed to decrease when there is additional generators which is important to achieve a better reliability of the system with reduced losses. Normally, it is assumed that losses decrease when generation takes place closer to the load site. According to [8], researchers concluded that solar power injection reduces the transmission losses but Figure 12 shows that locating distributed generators will be minimizing power losses at bus 5, 6 and 7, and maximizing power losses at bus 1, 2, 3 and 4. By comparing the power loss at bus 3 , 4 , there are slightly increase on power loss for each transmission line. This indicates that there is effect on power loss when at bus 3, 4 in case of with DG. Power loss will be significant decrease when the transmission line is closer to the location of DG and slightly increase when the location of distributed generators is far away. When fault occurs at bus 5, power loss is highest for the 2 cases. This indicates that protection devices need to be considered to reduce power loss. When a short to earth or power loss is greater than 0.1 per unit MVA occurs, protection is needed to disconnect all the equipment to save all lines. Impedance relay can be used for protection the transmission line. When a fault appears on the transmission line, the impedance setting in the relay is compared to the apparent impedance of the transmission line from the relay terminals to the fault. If the relay setting is determined to be below the apparent impedance it is determined that the fault is within the zone of protection.

\section{Stability Analysis}

Stability can be determined by the power-angle Formula (5) at both steady-state and transient. The power angle has 3 values, 2 at pre fault (the initial $\delta_{o}$ and maximum $\delta_{m}$ ) and one at transient (the critical $\delta_{c r}$ ). Critical angle is calculated at each bus when the fault occurs at any of the 7 bus and as referred to one of the 4 generators. Values given in Table 2, Table 3, impedances (2), (4) and Figure 4, Figure 7, Figure 10 are involved in the analysis. 


$$
\begin{array}{ll}
P_{i}=\frac{E_{i} V_{j}}{X_{T j}} \sin \delta+\frac{V_{j}^{2}\left(X_{T j}-X_{q i}\right)}{2 X_{T j} X_{q i}} \sin 2 \delta \quad \text { pre }- \text { fault } \\
P_{i}^{\prime}=\frac{E_{i}^{\prime} V_{j}^{\prime}}{X_{T j}^{\prime}} \sin \delta+\frac{V_{j}^{\prime 2}\left(X_{T j}^{\prime}-X_{q i}\right)}{2 X_{T j}^{\prime} X_{q i}} \sin 2 \delta \text { transient }
\end{array}
$$

where the subscripts, $i=1,2,3,4, j=1,2, \cdots, 7$.

$P_{i}$ is the mechanical turbine power at steady-state $=1$ per unit.

Steady-state values of voltages Figure 4 and reactance of the diagonal in (2) and (4) are substituted in the pre-fault Formula of (5) to obtain $\delta_{o}, \delta_{m}$. While the voltages Table 2, Table 3 and reactance values during fault are substituted in the transient form of (5) to obtain $\delta_{c r}$ by using equal area formula (A9).

Equal area criterion is applied to obtain the critical stability which relates to the critical clearing angle. Figure 13, Figure 14 are example of the equal area. Figure 13 shows the areas in a certain bus when the fault occurs at the same bus, where $P^{\prime}=0$ since its bus voltage drops to 0 , while Figure 14 shows the areas as related to another bus, where $P^{\prime} \neq 0$, since its bus voltage drops to a certain value.

Critical angle is obtained in degree by trial and error or MATLAB code taking several iterations for an accurate result. Tables 4-9 present the values obtained for the critical clearing angles in each bus due to fault occurs at each bus for the cases of without and with distributed generators as referred to each of the 4 generators. The empty slots indicates that the angle is indeterminate in which the power-angle curve at transient is closed to the steady-state curve, where the areas are undefined and thus the system shows that the stability is performed, since

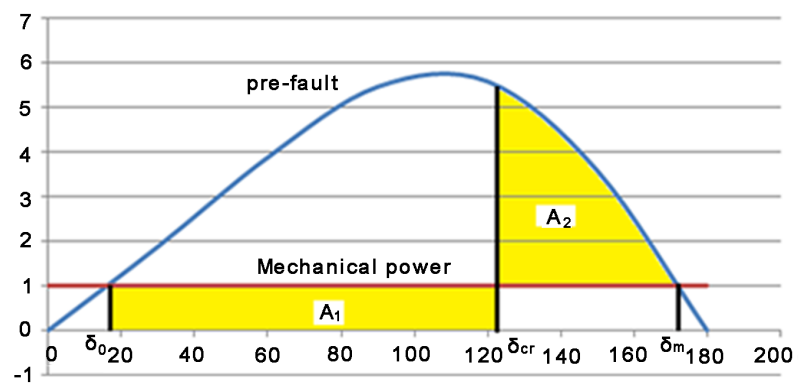

Figure 13. $P$ and $P$ 'curves when the fault occurs at the same bus.

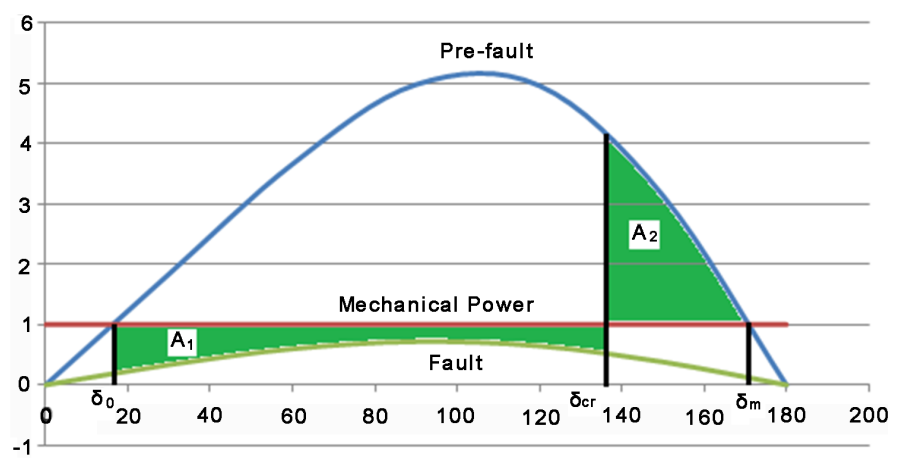

Figure 14. $P$ and $P$ 'curves when the fault occurs at different bus. 
Table 4. Critical angle at each bus as referred to G1, without DG.

\begin{tabular}{cccccccc}
\hline Bus & 1 & 2 & 3 & 4 & 5 & 6 & 7 \\
\hline 1 & 122.7 & 138.4 & 138.2 & 170 & & & \\
2 & 137.7 & 123.3 & 137.3 & 163.6 & & & \\
3 & 128.7 & 128.7 & 117.4 & 128.2 & & & \\
4 & 120.5 & 120.5 & 111.5 & 109.8 & & & \\
5 & 68.2 & 68.2 & 68.2 & 67.5 & 63 & 81.1 & 70.4 \\
6 & 81.5 & 64.6 & 61.2 & 68 & 65.1 & 60.9 & 63.7 \\
7 & 52.6 & 52.9 & 50.9 & 50.7 & 52.2 & 49.1 & 50.4 \\
\hline
\end{tabular}

Table 5. Critical angle at each bus as referred to G2, without DG.

\begin{tabular}{cccccccc}
\hline Bus & 1 & 2 & 3 & 4 & 5 & 6 & 7 \\
\hline 1 & 116.8 & 129.3 & 128.4 & 145 & & & \\
2 & 129 & 117.6 & 128 & 144.8 & & & \\
3 & 118.4 & 118.4 & 110.2 & 123.3 & & & \\
4 & 110.6 & 110.6 & 102 & 101.4 & 128.2 & & \\
5 & 63.1 & 63.1 & 63.1 & 62.5 & 60 & 60.7 & 69.3 \\
6 & 62 & 62 & 60 & 60.1 & 62.2 & 60.13 .8 & 64.7 \\
7 & 56.2 & 55 & 54.1 & 54 & 55.4 & 51.4 & 51.5 \\
\hline
\end{tabular}

Table 6. Critical angle at each bus as referred to G1 and with DG.

\begin{tabular}{cccccccc}
\hline Bus & 1 & 2 & 3 & 4 & 5 & 6 & 7 \\
\hline 1 & 127.2 & & 163.3 & & & & \\
2 & 165.8 & 127.9 & 156.6 & & & & \\
3 & 166.3 & 161.8 & 126.4 & 161.8 & & & \\
4 & 164.7 & 159.4 & 126.2 & 121.8 & & & 164.7 \\
5 & & & 136 & 131 & 104 & 130.9 & \\
6 & & & & & 147.7 & 109.2 & \\
7 & & & 151.8 & 137 & 113.9 & 91.6 & 74.9 \\
\hline
\end{tabular}

Table 7. Critical angle at each bus as referred to G2 and with DG.

\begin{tabular}{cccccccc}
\hline Bus & 1 & 2 & 3 & 4 & 5 & 6 & 7 \\
\hline 1 & 122.6 & 139.2 & 135 & 154.6 & & & \\
2 & 139.6 & 123.2 & 134.7 & 154.3 & & & \\
3 & 138.2 & 137.3 & 121.5 & 136 & & & \\
4 & 133.7 & 132.7 & 118.5 & 116 & & & \\
5 & 110.7 & 110 & 99.5 & 125 & 97.1 & 125 & 152.5 \\
6 & & & 138.5 & 134.7 & 120.1 & 103.5 & \\
7 & 119 & 119 & 105.6 & 103.1 & 95.5 & 85.5 & 85.5 \\
\hline
\end{tabular}


Table 8. Critical angle at each bus as referred to G3 and with DG.

\begin{tabular}{cccccccc}
\hline Bus & 1 & 2 & 3 & 4 & 5 & 6 & 7 \\
\hline 1 & 134 & & 164.5 & & & & \\
2 & & 140.2 & 161.8 & & & & \\
3 & & 145 & 143.7 & 155 & & & \\
4 & & 140.5 & 136.5 & & & \\
5 & & 156 & 151 & 124.7 & 151.1 & \\
6 & & & & 166.2 & 127.6 & \\
7 & & & & 166.9 & 138.1 & 115.4 & 114.8 \\
\hline
\end{tabular}

Table 9. Critical angle at each bus as referred to G4 and with DG.

\begin{tabular}{cccccccc}
\hline Bus & 1 & 2 & 3 & 4 & 5 & 6 & 7 \\
\hline 1 & 142.6 & 146.9 & 146 & 147.9 & 168.2 & 173.3 & \\
2 & 148.6 & 143 & 147.4 & 151.2 & 150.2 & & \\
3 & 146.6 & 146.4 & 142.3 & 146.4 & 162.5 & 168.8 & \\
4 & 141.1 & 143.9 & 140.4 & 139.1 & 153.9 & 157.5 & 171.8 \\
5 & 135.9 & 135.8 & 133.2 & 132.8 & 129.1 & 132.8 & 140.9 \\
6 & 142.4 & 142.4 & 141.2 & 138.8 & 136.3 & 131.8 & 141.1 \\
7 & 128.5 & 128.5 & 126.4 & 125.9 & 124.1 & 120.5 & 120.7 \\
\hline
\end{tabular}

the generator is not swinging. Figure 15 illustrates one case for indeterminate the critical angle.

It can be recognized from results in Table 4 and Table 5 that when the distributed load bus 6, 7 have no generators connected the chance of instability occur in the power stations generators 1 and 2 is high since the critical angle in bus 5, 6 and 7 are low for any fault can occur at any bus. But when connecting the distributed generators to bus 6 and 7, the critical angles increase at these buses from the results of Table 6, Table 7, which means that the stability is improved for generators 1 and 2, although the fault currents are high in these buses as compared to without distributed generators case. For the results of Table 8, Table 9 it is believed that the distributed generators 3,4 are seems to be stables for any fault can occur at any bus since the values of critical angle is moderate.

Critical clearing time can therefore be found from the Form (6) which gives the maximum clearing time period before instability and is used as the operating time in the over current relay to obtain the multiple time setting. Figures 16-19 show the critical time values in second in each bus as referred to the generators.

The time of Equation (6) is obtained from the inverse integral of load angle in the power form which includes inertial, damping and synchronizing power coefficients with Form (5).

$$
t_{c r}=\sqrt{\frac{2 J\left(\delta_{c r}-\delta_{o}\right) \pi}{180 P_{i}}}
$$

where $J$ is the moment of inertia which is assumed to be 2 per unit and $\delta_{o}$ is the initial angle calculated from the pre-fault Form of (5). 


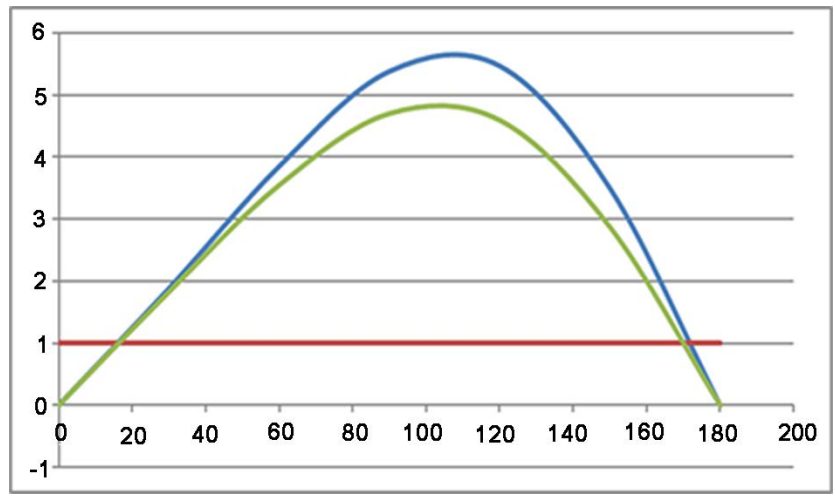

Figure 15. $P$ and $P$ 'curves at bus 3 when fault occurs at bus 5 .

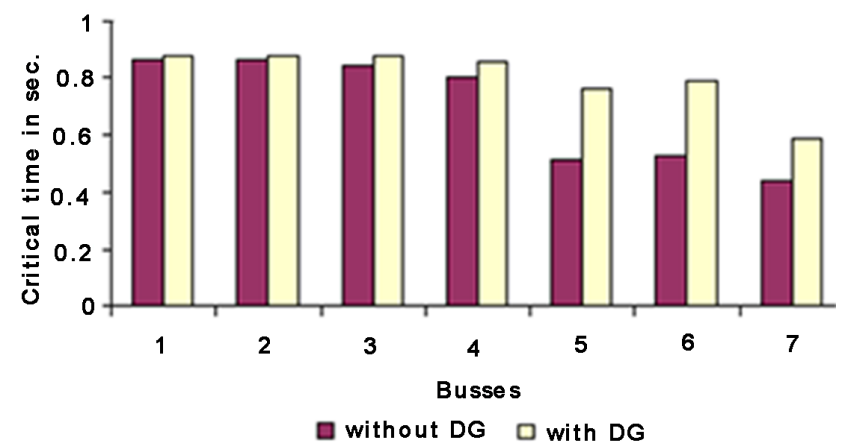

Figure 16. Critical time in each bus as referred to G1.

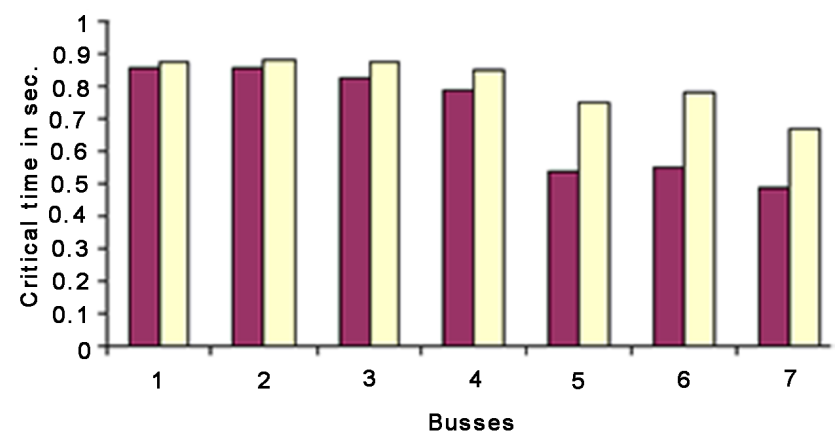

$\square$ without DG $\square$ with DG

Figure 17. Critical time in each bus as referred to G2.

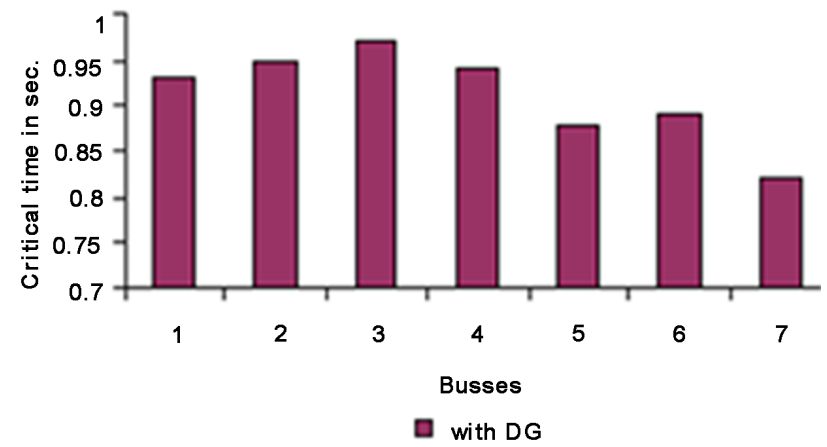

Figure 18. Critical time in each bus as referred to G3. 


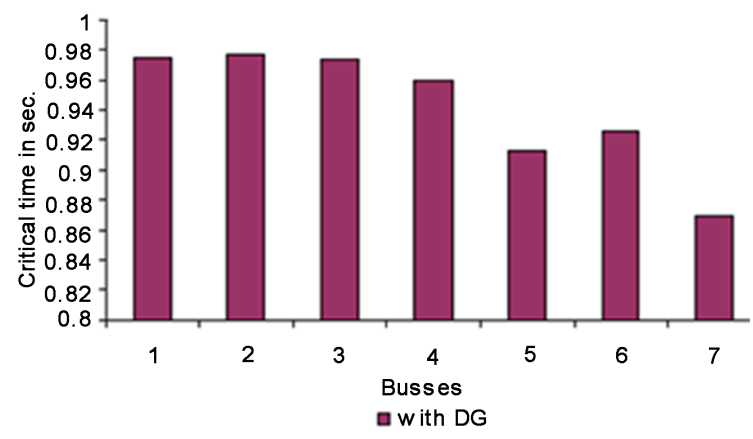

Figure 19. Critical time in each bus as referred to G4.

It is seen that when the distributed generators are injected in the load busses the critical time increased in all busses which indicates that it give more time to clear before instability. This states that grid with distributed generators is more stable than the grid without distributed generators, although the fault currents are much higher.

\section{Protection}

This section determines the selection of current transformers for over current relays types $\mathrm{CO} 8, \mathrm{CO} 9$ and $\mathrm{CO} 11$, which relates to standard inverse SI, very inverse VI and extremely inverse EI, respectively. This is followed by calculating time multiple setting TMS and current settings of the relay at each bus considering the optimum fault currents and operating times are the minimum values given in Figure 9, Figure 16, Figure 17. Table 10 summarizes the per unit currents, actual current in Amper and operating times in sec.

The base currents are calculated from the base voltage at each bus and 500 MVA base powers using the Formula (7)

$$
S=\sqrt{3} V_{i} I^{*}, i=1,2, \cdots, 7
$$

The distributed bus 6, 7 are protected from the feeders, 3 feeders connected to bus 6 and 20 to bus 7 .

Current transformers therefore, can be selected based on the values of actual fault current given in Table 10. Pick up current $I_{p}$ and current settings as well as the time multiple setting for each relay type are then determined From (8) and given in Table 11, Table 12.

$$
\begin{aligned}
& \text { ST (CO8) } t_{o}=T M S \frac{0.14}{\left(\frac{I_{f}}{I_{p}}\right)^{0.02}-1} \\
& \text { VI (CO9) } t_{o}=T M S \frac{13.5}{\left(\frac{I_{f}}{I_{p}}\right)-1} \\
& \text { EI (CO11) } t_{o}=T M S \frac{80}{\left(\frac{I_{f}}{I_{p}}\right)^{2}-1}
\end{aligned}
$$


Table 10. Per unit fault current and critical time at each bus.

\begin{tabular}{cccccccc}
\hline Bus & 1 & 2 & 3 & 4 & 5 & 6 & 7 \\
\hline $\mathrm{I}_{\mathrm{f}} \mathrm{pu}$ & 2.18 & 2.19 & 2.09 & 1.79 & 0.98 & 0.97 & 0.72 \\
$\mathrm{I}_{\mathrm{f}} \mathrm{A}$ & 2289 & 2299 & 2194 & 3915 & 2143 & 2828 & 1575 \\
$\mathrm{t}_{\text {cr }}$ & 0.852 & 0.856 & 0.825 & 0.784 & 0.516 & 0.527 & 0.436 \\
\hline
\end{tabular}

Table 11. Current transformer settings in each bus and relay type.

\begin{tabular}{cccccccc}
\hline Bus & 1 & 2 & 3 & 4 & 5 & 6 & 7 \\
\hline CT & $2000 / 5$ & $2000 / 5$ & $2000 / 5$ & $4000 / 5$ & $2000 / 5$ & $2500 / 5$ & $1500 / 5$ \\
$\mathrm{I}_{\mathrm{f}} / \mathrm{I}_{\mathrm{P}}$ & 5.7225 & 5.7475 & 5.485 & 4.8937 & 5.3575 & 5.656 & 5.25 \\
SI & 3.9432 & 3.9338 & 4.0431 & 4.3385 & 4.1008 & 3.9703 & 4.1517 \\
VI & 2.8586 & 2.8436 & 3.0100 & 3.4671 & 3.0981 & 2.8995 & 3.1764 \\
EI & 2.5199 & 2.4974 & 2.7505 & 3.4861 & 2.8878 & 2.5814 & 3.0117 \\
\hline
\end{tabular}

Table 12. TMS sec. in each relay.

\begin{tabular}{cccccccc}
\hline Bus & 1 & 2 & 3 & 4 & 5 & 6 & 7 \\
\hline SI & 0.216 & 0.217 & 0.204 & 0.181 & 0.126 & 0.133 & 0.105 \\
VI & 0.298 & 0.301 & 0.274 & 0.226 & 0.167 & 0.182 & 0.137 \\
EI & 0.338 & 0.343 & 0.3 & 0.225 & 0.179 & 0.204 & 0.145 \\
\hline
\end{tabular}

By this setting relays will trip slightly before critical time when a symmetric fault occurs at its bus.

\section{Conclusions}

A detailed analysis and computation are presented in this paper for load flow, short circuit, stability and protection by taking a simple example of a limited 7-bus power grid system in 2 cases, without and with distributed generators. Calculations of bus voltages at steady-state and transient with fault current at each bus are investigated and compared by Gauss method and impedance matrix in per unit values. Stability analysis based on power-angle characteristics and equal area criterion to calculate the critical load angle and critical clearing time for the 2 cases is given for each bus when a symmetric 3-phase fault occurs at each bus. This is followed by selecting suitable current transformers and setting the current and time multiple setting of three types of over current relays that are set to trip at critical stability time to protect the system.

Optimum values of bus voltages are determined to select a suitable slack bus that gives lower power loss in the grid. The results show that injecting distributed generators doesn't have any negative impact on the grid, but helps to reserve the energy consumption in the load bus. Moreover, distributed generators make the grid system more stable. This is because of the increasing value of critical clear- 
ing angle in the result of with distributed generators in most of busses for any fault location.

However, penetration of any distributed generators into a power grid system causes an increase in the fault level of the network at any fault location. Presence of the distributed generators in a location close to the substation or bus bar causes a decrease in the bus voltage during fault and the bus voltage will be increase for bus bar that is far away from the fault location but the fault current is still increased. As the distance between the bus bar and the fault location increases, the value of the bus voltage increases. In the 3-phase fault, the voltages at faulted bus phases dropped to zero during the fault.

\section{References}

[1] Kundur, P., Paserba, J., Ajjarapu, V., Anderson, G., Bose, A., Canizares, C., Hatziargyriou, N., Hill, D., Stankovic, A., Taylor, C., Custem, T.V. and Vittal, V. (2004) Definition and Classification of Power System Stability. IEEE Transactions on Power Systems, 19, 1387-1401. https://doi.org/10.1109/TPWRS.2004.825981

[2] Lee, B.H. and Lee, K.Y. (1991) A Study on Voltage Collapse Mechanism in the Electric Power System. Transactions on Power Systems, 6, 966-974.

https://doi.org/10.1109/59.119236

[3] Tran-Quoc, T., Vu-Due, T., Feuillet, R., Hadjsaid, N., Sabonnadire, J.C., Praing, C, H. and Tran-Dinh, L. (1998) Dynamic Analysis on the Voltage Instability in the Vietnam System. Proceedings of 1998 International Conference on Energy Management and Power Delivery, Singapore, 5 March 1998. https://doi.org/10.1109/EMPD.1998.705497

[4] Van Cutsem, T. (2000) Voltage Instability: Phenomena, Countermeasures, and Analysis Methods. Proceeding of the IEEE, 88, 208-227.

https://doi.org/10.1109/5.823999

[5] Syafil, K.M.N. (2013) Renewable Distributed Generation Models in Three-Phase Load Flow Analysis for Smart Grid. Indonesian Journal of Electrical Engineering and Computer Science, 11, 661-668.

[6] Singh, M. and Mahapatra, S. (2016) Analysis of Symmetrical Fault in IEEE 14-Bus System for Enhancing over Current Protection Scheme. International Journal of Future Generation and Networking, 9, 51-62. https://doi.org/10.14257/ijfgen.2016.9.4.05

[7] Nallagalva, S.K., Kirar, M.K. and Agnihotri, G. (2012) Transient Stability Analysis of the IEEE 9-Bus Electric Power System. International Journal of Scientific Engineering and Technology, 1, 161-166.

[8] Barsoum, N. and Lee, C.Z. (2013) Simulation of Power Flow and Protection of a Limited Bus Grid System with Injection Solar Power. Journal of Power and Energy Engineering, 5, 59-69. https://doi.org/10.4236/epe.2013.51008 


\section{Appendix}

Admittance matrix $=\left[Y_{i i}=\frac{1}{Z_{i i}}+\sum \frac{1}{Z_{i j}}, Y_{i j}=\frac{1}{Z_{i j}}\right]$

Impedance matrix $[Z]=[Y]^{-1}$

Gauss-Seidel bus voltage $V_{i}^{k+1}=\frac{\frac{P_{i}-j Q_{i}}{V_{i}^{* k}}-\sum_{\substack{j=0 \\ i \neq j}}^{n} Y_{i j} V_{j}^{k}}{Y_{i i}}$

Bus current $I_{i}=Y_{n n} V_{i}^{n}$

Line flow $S_{i j}=V_{i} I_{i j}^{*}, S_{j i}=V_{j} I_{j i}^{*}$

Line Loss $S_{L i j}=S_{i j}+S_{j i}$

Fault current $I_{f i}=\frac{V_{i}^{n}}{Z_{i i}}$

Transient bus voltage $V_{i}=1-Z_{i j} I_{f i}$

Equal area criteria

$$
A_{1}=P_{m}\left(\delta_{o}-\delta_{c r}\right)-\int_{\delta_{o}}^{\delta_{c r}} P^{\prime} \mathrm{d} \delta=A_{2}=\int_{\delta_{c r}}^{\delta_{m}} P \mathrm{~d} \delta-P_{m}\left(\delta_{m}-\delta_{c r}\right)
$$

\section{Scientific Research Publishing}

\section{Submit or recommend next manuscript to SCIRP and we will provide best} service for you:

Accepting pre-submission inquiries through Email, Facebook, LinkedIn, Twitter, etc. A wide selection of journals (inclusive of 9 subjects, more than 200 journals) Providing 24-hour high-quality service User-friendly online submission system Fair and swift peer-review system Efficient typesetting and proofreading procedure Display of the result of downloads and visits, as well as the number of cited articles Maximum dissemination of your research work

Submit your manuscript at: http://papersubmission.scirp.org/ Or contact jpee@scirp.org 